\title{
IMPLEMENTASI MEDIA BERBASIS TEKNOLOGI INFORMASI SEBAGAI MEDIA PEMBELAJARAN OLEH GURU BIOLOGI DI SMA NEGERI SE-KABUPATEN DELI SERDANG
}

\author{
Jhonas Dongoran, Dian Arisetya \\ Surel: dongoran231089@gmail.com
}

\begin{abstract}
This study aims to describe the availability of IT-based learning media in Deli Serdang District High School. This study uses a type of quantitative research with descriptive methods. the population is all Se-regency district biology teachers. The subjects in this study were biology teachers in class XI. From the results of the questionnaire regarding the completeness of ITbased learning media for Tanjung Morawa 1 Public High School, Percut Seituan 1 Public High School, and 1 Pancur Batu Public High School obtained a percentage of 55.56\% and for Namorambe 1 Public High School, Bangun Purba 1 Public High School and Public High School 1 Galagng obtained a percentage of $44.44 \%$. From the results of the questionnaire regarding the condition of IT-based learning media for Namorambe 1 Public High School amounting to 11.11\%, for State High School 1 Percut Sei Tuan, Galan 1 High School and Panacur Batu 1 High School at 55.56\%, for Tanjung Morawa 1 Public High School and Bangun Purba 1 Public High School at $33.33 \%$.
\end{abstract}

Keywords: Media, Information Technology, Implementation

\begin{abstract}
ABSTRAK
Penelitian ini bertujuan untuk mendeskripsikan ketersediaan media pembelajaran berbasis TI di SMA Negeri Se-Kabupaten Deli Serdang. Penelitian ini menggunakan jenis penelitian kuantitatif dengan metode deskriptif. populasi adalah seluruh guru biologi Se-kabupaten Deli serdang. Subjek dalam penelitian ini adalah guru biologi kelas XI. Dari hasil angket mengenai kelengkapan media pembelajaran berbasis TI untuk SMA Negeri 1 Tanjung Morawa, SMA Negeri 1 Percut Seituan, dan SMA Negeri 1 Pancur batu diperoleh presentase sebesar 55,56\% dan untuk SMA Negeri 1 Namorambe, SMA Negeri 1 Bangun Purba dan SMA Negeri 1 Galagng diperoleh persentase sebesar $44,44 \%$. Dari hasil angket mengenai kondisi media pembelajaran berbasis TI untuk SMA Negeri 1 Namorambe sebesar $11,11 \%$, untuk SMA Negeri 1 Percut Sei Tuan, SMA Negeri 1 Galan dan SMA Negeri 1 Panacur Batu sebesar 55,56\%, untuk SMA Negeri 1 Tanjung Morawa dan SMA Negeri 1 Bangun Purba sebesar 33,33\%.
\end{abstract}

Kata Kunci : Media, Teknologi Informasi, Implementasi

\section{PENDAHULUAN}

Pada era Teknologi Informasi saat ini penggunaan komputer tidak lagi terbatas pada bidang-bidang pekerjaan administratif, namun telah meluas sampai bidang penyebarluasan informasi untuk khalayak. Dalam hal ini, komputer berfungsi sebagai media yang efektif, efisien, dan canggih karena didukung oleh program-program yang ada didalamnya.

Guru menjadi salah satu penentu keberhasilan dalam setiap 
Jhonas Dongoran, Dian Arisetya : Implementasi Media Berbasis ...

proses pem-belajaran. Keberadaan guru menjadi sangat penting dalam proses pembelajaran. Sehingga dengan perannya tersebut, profesionalisme menjadi wajib dimiliki oleh seorang guru.

Dimyati dan Mudjiono (2013) mengemukakan bahwa adanya media dan sumber belajar akan mempengaruhi proses pembelajaran karena dapat membantu siswa mempermudah pemahaman tentang materi yang diajarkan. Menurut Kustandi dan Sutjipto (2011) dilihat dari sifat atau jenisnya, media dapat dikelompokkan menjadi tiga kelompok, yaitu media auditif, media visual, dan media audio visual.

\begin{tabular}{lr}
\multicolumn{3}{c}{ Berdasarkan latar belakang } \\
yang telah dijabarkan, dapat \\
disimpulkan bahwa & media \\
pembelajaran berbasis TI sangat
\end{tabular} bermanfaat dalam pembelajaran. Oleh karena itu, peneliti tertarik untuk melakukan analisis penelitian dengan judul "Implementasi Media Berbasis Teknologi Informasi Sebagai Media Pembelajaran Oleh Guru Biologi Di Sma Negeri SeKabupaten Deli Serdang".

Penelitian ini bertujuan: 1) Untuk mendeskripsikan ketersediaan media pembelajaran berbasis TI di SMA Negeri Se-Kabupaten Deli Serdang, 2) Untuk mendeskripsikan pemanfaatan media pembelajaran berbasis TI di SMA Negeri SeKabupaten Deli Serdang, 3) Untuk mendeskripsikan penerapan media berbasis Teknologi Informasi oleh Guru Biologi di kelas XI SMA
Negeri Se-Kabupaten Deli Serdang, dan 4) Untuk mendeskripsikan permasalahan dan hambatan yang dialami guru Biologi dalam penerapan Media Berbasis Teknologi Informasi di kelas XI SMA Negeri Se-Kabupaten Deli Serdang.

\section{METODE PENELITIAN}

Penelitian ini dilaksanakan di SMA Negeri Se-Kabupaten Deli Serdang yang terdiri dari 6 sekolah SMA Negeri 1 Tanjung Morawa, SMA Negeri 1 Percut Sei Tuan, SMA Negeri 1 Bangun Purba, SMA Negeri 1 Galang, SMA Negeri 1 Namorambe, dan SMA Negeri 1 Pancur Batu. Dalam penelitian ini yang menjadi populasi adalah seluruh guru biologi Se-kabupaten Deli serdang. Subjek dalam penelitian ini adalah guru biologi kelas X, XI, XII. Penelitian ini menggunakan jenis penelitian kuantitatif dengan metode deskriptif.

Dalam penelitian ini, peneliti menggunakan teknik pengumpulan data yang berupa angket, observasi, dan wawancara tidak terstruktur.

Data yang diperoleh dari responden akan dibandingkan dengan intervalnya dan dikategorikan menjadi tiga kategori disetiap indikator, yaitu kategori rendah, sedang, dan tinggi. Azwar (2015) memberikan panduan seperti dalam Tabel 1. 
Tabel 1. Kategori Interval

\begin{tabular}{cc}
\hline Interval & Kategori \\
\hline $\mathbf{X}>\left(\boldsymbol{\mu}-\mathbf{1 , 0} \mathbf{o}^{*}\right)$ & Rendah \\
\hline$\left(\boldsymbol{\mu}-\mathbf{1 , 0} \mathbf{0}^{*}\right) \leq \mathbf{X}<(\boldsymbol{\mu}-\mathbf{1 , 0} \mathbf{0})$ & Sedang \\
\hline$\left(\boldsymbol{\mu}-\mathbf{1 , 0} \mathbf{0}^{*}\right) \leq \mathbf{X}$ & Tinggi \\
\hline
\end{tabular}

\section{HASIL PENELITIAN DAN PEMBAHASAN}

\section{Indikator Kelengkapan Media Pembelajaran Berbasis TI}

Tabel 2. Kategori Interval pada Indikator Kelengkapan Media Pembelajaran Berbasis TI

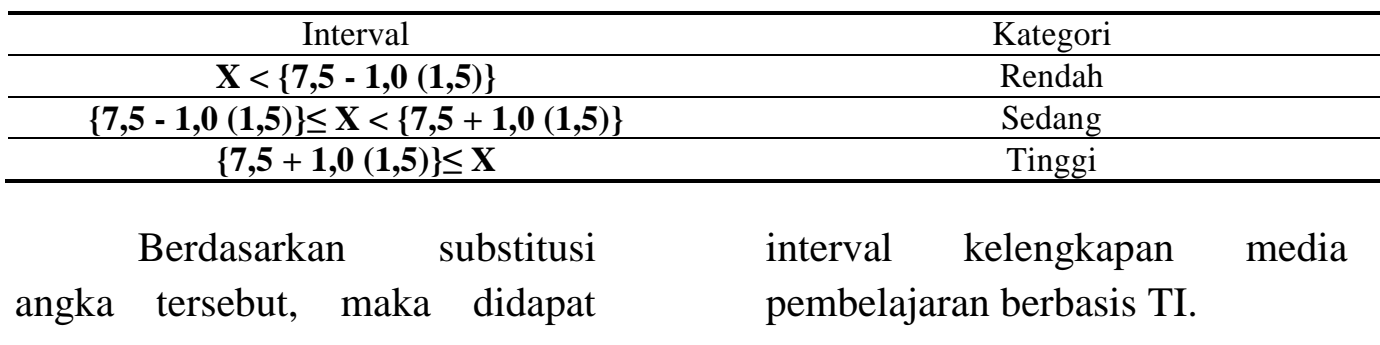

Tabel 3. Kategori Interval pada Indikator Kelengkapan Media Pembelajaran Berbasis TIK

\begin{tabular}{cc}
\hline Interval & Kategori \\
\hline $\mathbf{X}<\mathbf{6}$ & Rendah \\
\hline $\mathbf{6} \leq \mathbf{X}<\mathbf{9}$ & Sedang \\
\hline $\mathbf{9} \leq \mathbf{X}$ & Tinggi \\
\hline
\end{tabular}

Distribusi frekuensi pada berbasis TIK dapat dibaca pada kelengkapan media pembelajaran Tabel 4. berikut ini:

Tabel 4. Distribusi Frekuensi pada Kelengkapan Media Pembelajaran Berbasis TIK

\begin{tabular}{cccc}
\hline Interval & Kategori & Frekuensi & Persentase \\
\hline $\mathrm{X}<6$ & Rendah & - & $0 \%$ \\
\hline $6 \leq \mathrm{X}<9$ & Sedang & 15 & $55,56 \%$ \\
\hline $9 \leq \mathrm{X}$ & Tinggi & 12 & $44,44 \%$ \\
\hline & Jumlah & & $100 \%$ \\
\hline
\end{tabular}

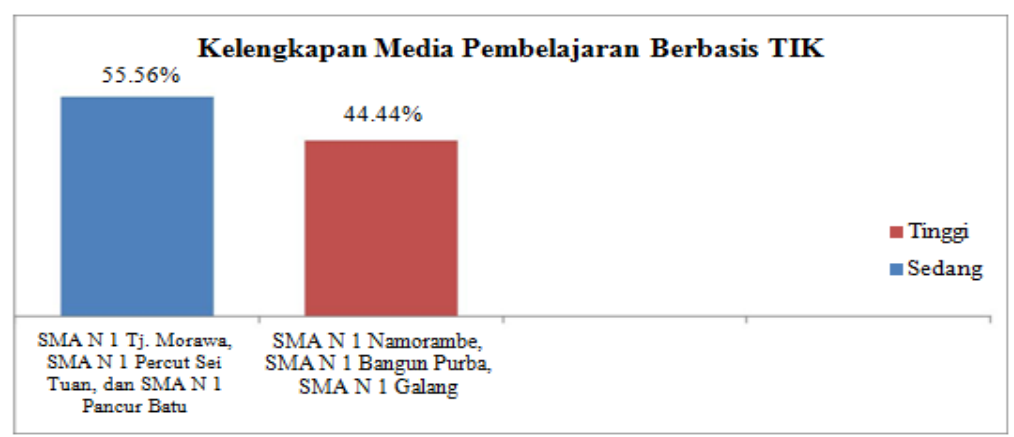


Jhonas Dongoran, Dian Arisetya : Implementasi Media Berbasis ...

Gambar 1. Kelengkapan Media Pembelajaran Berbasis TI

Indikator Kondisi Media Pembelajaran Berbasis TI

Tabel 5. Distribusi Frekuensi pada Kondisi Media

Pembelajaran Berbasis TI

\begin{tabular}{ccccl}
\hline Interval & Kategori & Frekuensi & Persentase & \multicolumn{1}{c}{ Nama Sekolah } \\
\hline $\mathbf{X}<\mathbf{1 0}$ & Rendah & $\mathbf{3}$ & $11,11 \%$ & SMA Negeri 1 Namorambe \\
\hline $\mathbf{1 0} \leq \mathbf{X}<\mathbf{1 5}$ & Sedang & $\mathbf{1 5}$ & $55,56 \%$ & $\begin{array}{l}\text { SMA Negeri 1 Percut Sie Tuan } \\
\text { SMA Negeri 1 Galang } \\
\text { SMA Negeri 1 Pancur Batu }\end{array}$ \\
\hline $\mathbf{1 5} \leq \mathbf{X}$ & Tinggi & $\mathbf{9}$ & $33,33 \%$ & $\begin{array}{l}\text { SMA Negeri 1 Tanjung Morawa } \\
\text { SMA Negeri 1 Bangun Purba }\end{array}$ \\
\hline \multicolumn{7}{c}{ Jumlah } & & $100 \%$ & \\
\hline
\end{tabular}

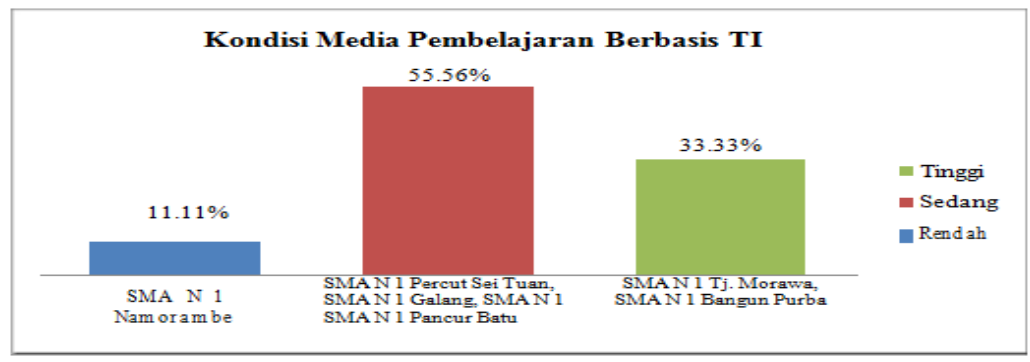

Gambar 2. Kondisi Media Pembelajaran Berbasis TI

Indikator Pemeliharaan Media Pembelajaran Berbasis TI

Tabel 6. Distribusi Frekuensi pada Pemeliharaan Media Pembelajaran Berbasis TI

\begin{tabular}{ccccl}
\hline Interval & Kategori & Frekuensi & Persentase & \multicolumn{1}{c}{ Nama Sekolah } \\
\hline $\mathbf{X}<\mathbf{6}$ & Rendah & $\mathbf{3}$ & $11,11 \%$ & SMA Negeri 1 Namorambe \\
\hline $\begin{array}{c}\mathbf{1 0} \leq \mathbf{X}< \\
\mathbf{9}\end{array}$ & Sedang & $\mathbf{1 2}$ & $44,45 \%$ & $\begin{array}{l}\text { SMA Negeri 1 Percut Sie Tuan } \\
\text { SMA Negeri 1 Galang } \\
\text { SMA Negeri 1 Pancur Batu }\end{array}$ \\
\hline $\mathbf{9} \leq \mathbf{X}$ & Tinggi & $\mathbf{1 2}$ & $44,44 \%$ & $\begin{array}{l}\text { SMA Negeri 1 Tanjung Morawa } \\
\text { SMA Negeri 1 Bangun Purba }\end{array}$ \\
\hline & Jumlah & & $100 \%$ & \\
\hline
\end{tabular}

Indikator Pengetahuan Guru terhadap Media Pembelajaran Berbasis TI

Tabel 7. Distribusi Frekuensi pada Pengetahuan Guru terhadap Media Pembelajaran Berbasis TI

\begin{tabular}{cccc}
\hline Interval & Kategori & Frekuensi & Persentase \\
\hline $\mathrm{X}<6$ & Rendah & 16 & $59,26 \%$ \\
\hline $6 \leq \mathrm{X}<9$ & Sedang & 7 & $25,93 \%$ \\
\hline $9 \leq \mathrm{X}$ & Tinggi & 4 & $14,81 \%$ \\
\hline
\end{tabular}




Jumlah 100

$\overline{\text { Indikator Upaya Guru Meningkatkan Kemampuan Memanfaatkan Media }}$ Pembelajaran Berbasis TI

Tabel 8. Distribusi Frekuensi Upaya Guru Meningkatkan Kemampuan Memanfaatkan Media Pembelajaran Berbasis TI

\begin{tabular}{cccc}
\hline Interval & Kategori & Frekuensi & Persentase \\
\hline \hline $\mathrm{X}<8$ & Rendah & 15 & $55,56 \%$ \\
\hline \hline $8 \leq \mathrm{X}<12$ & Sedang & 12 & $44,44 \%$ \\
\hline \hline $12 \leq \mathrm{X}$ & Tinggi & - & - \\
\hline \hline & Jumlah & & $100 \%$ \\
\hline
\end{tabular}

Indikator Pembuatan Media Pembelajaran Berbasis TI

Tabel 9. Distribusi Frekuensi pada Pembuatan Media Pembelajaran Berbasis TI

\begin{tabular}{cccc}
\hline Interval & Kategori & Frekuensi & Persentase \\
$\mathrm{X}<10$ & Rendah & 19 & $70,37 \%$ \\
$10 \leq \mathrm{X}<15$ & Sedang & 8 & $29,63 \%$ \\
$15 \leq \mathrm{X}$ & Tinggi & - & - \\
& Jumlah & & $100 \%$ \\
\hline
\end{tabular}

Indikator Relevansi dengan Tujuan Pembelajaran

Tabel 10. Kategori Interval pada Indikator Relevansi dengan Tujuan Pembelajaran

\begin{tabular}{cc}
\hline Interval & Kategori \\
$X<6$ & Rendah \\
$6 \leq X<9$ & Sedang \\
$9 \leq X$ & Tinggi \\
\hline
\end{tabular}

Indikator Relevansi dengan Materi Pembelajaran

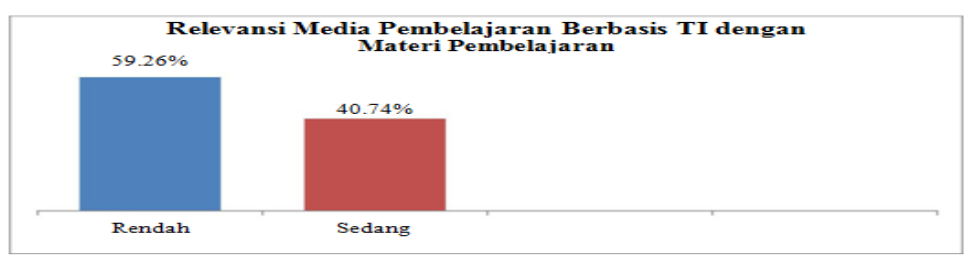

Gambar 3. Relevansi Media Pembelajaran Berbasis TI dengan Materi Pembelajaran 
Indikator Relevansi dengan Karakteristik Siswa

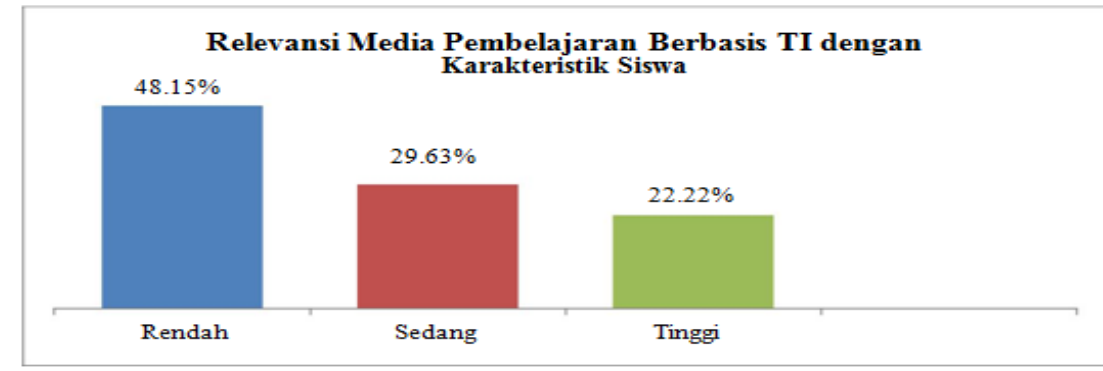

Gambar 4. Relevansi Media Pembelajaran Berbasis TI dengan Karakteristik Siswa

\section{Indikator Relevansi Media Pembelajaran Berbasis TI dengan Teori}

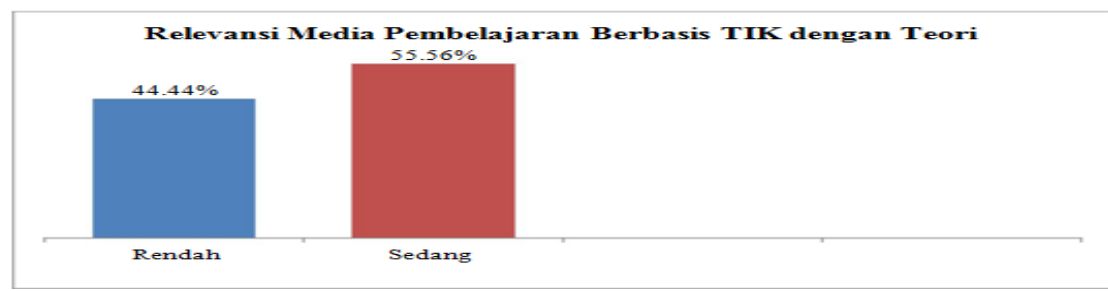

Gambar 5. Relevansi Media Pembelajaran Berbasis TI dengan Teori

Indikator Relevansi dengan Kondisi Lingkungan, Fasilitas Pen-dukung, dan Waktu

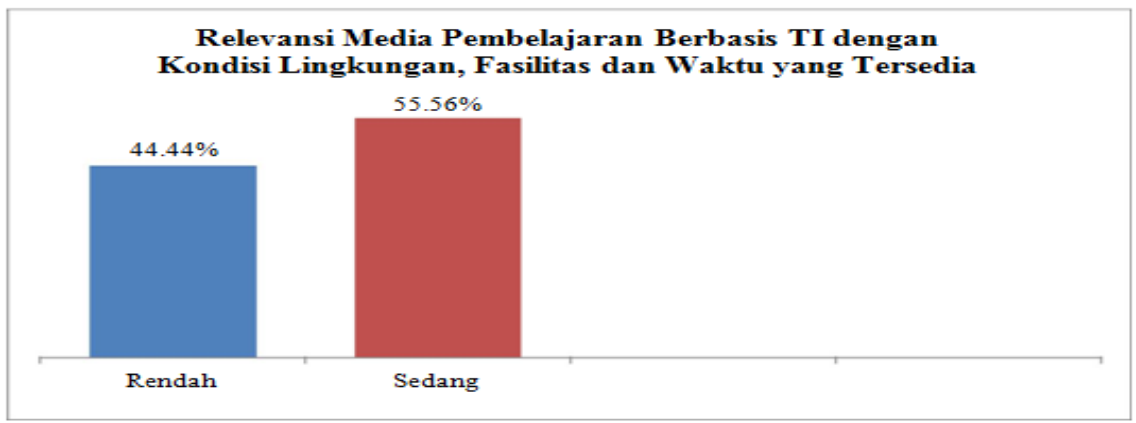

Gambar 6. Relevansi Media Pembelajaran Berbasis TI dengan Kondisi Lingkungan, Fasilitas, dan Waktu yang Tersedia

\section{Ringkasan Perhitungan Variabel Pemanfaatan Media Pembelajaran Berbasis TI}

Tabel 11. Kategori Interval Pemanfaatan Media Pembelajaran Berbasis TI

\begin{tabular}{cc}
\hline Interval & Kategori \\
\hline $\mathrm{X}<64$ & Rendah
\end{tabular}




\begin{tabular}{cll}
\hline \multicolumn{4}{c}{$64 \leq \mathrm{X}<96$} \\
$96 \leq \mathrm{X}$ & berbasis TI di SMA Negeri Se- \\
\hline \multicolumn{3}{c}{ Berdasarkan hasil rekapitulasi, } \\
skor rata-rata pemanfaatan media & Kabupaten Deli Serdang masuk \\
pembelajaran berbasis TI SMA & dalam kategori rendah. Hal ini \\
Negeri Se-Kabupaten Deliserdang & dikarenakan skor 55,81 berada pada \\
adalah 55,81. Ini menunjukkan bahwa & interval X $<64$.
\end{tabular}
pemanfaatan media pembelajaran

Penerapan media dalam proses Pembelajaran biologi di Sekolah Menengah Atas Kabupaten Deliserdang

Tabel 12. Rekapitulasi Penerapan Media Pembelajaran Berbasis TI Oleh Guru

\begin{tabular}{ccccccc}
\hline No & Nama Sekolah & $\begin{array}{c}\text { Jlh } \\
\text { Guru }\end{array}$ & & \multicolumn{2}{c}{ Betuk Media Pembelajaran } \\
\cline { 3 - 6 } & & $\begin{array}{c}\text { Power } \\
\text { Point }\end{array}$ & $\begin{array}{c}\text { CD Media Ajar } \\
\text { Berbasis HTML }\end{array}$ & $\begin{array}{c}\text { Video } \\
\text { Pembelajaran }\end{array}$ & $\begin{array}{c}\text { Multimedia } \\
\text { Interaktif }\end{array}$ \\
\hline $\mathbf{1}$ & SMA Negeri 1 Tj. Morawa & 5 & 3 & 0 & 0 \\
\hline $\mathbf{2}$ & $\begin{array}{l}\text { SMA Negeri 1 Percut Sei } \\
\text { Tuan }\end{array}$ & 5 & 2 & 0 & 0 \\
\hline $\mathbf{3}$ & SMA Negeri 1 Bangun Purba & 4 & 2 & 0 & 0 \\
\hline $\mathbf{4}$ & SMA Negeri 1 Galang & 3 & 1 & 0 & 0 \\
\hline $\mathbf{5}$ & SMA Negeri 1 Namorambe & 5 & 2 & 0 & 0 \\
\hline $\mathbf{6}$ & SMA Negeri 1 Pancur Batu & 4 & 3 & & 0 \\
\hline & Total & $\mathbf{2 7}$ & $\mathbf{1 3}$ & & 0 \\
\hline
\end{tabular}

Menurut Priyayi (2016) guru merupakan salah satu penanggung jawab pembelajaran di sekolah. Guru memiliki peranan penting dalam pengelolaan faktor yang mempengaruhi belajar siswa. Konseptentang guru sebagai satusatunya sumber belajar, dapat dirubah menjadi belajar berbasis aneka sumber belajar. Media pembelajaran dapat berfungsi sebagai sumber belajar yang efektif. Guru perlu menggunakan media yang dapat memaksimalkan proses pembelajaran di kelas. Pada prakteknya banyak faktor yang mempengaruhi penggunaan media pembelajaran.

Hasil penelitian menyatakan faktor faktor yang mempengaruhi penggunaan media antara lain : 1) Ketersediaan dan kondisi media, 2) ketersediaan jaringan internet, 3) guru kurang menguasai dan memahami dalam mengoperasikan media berbasis TI. Guru lebih mudah menggunakan media yang sudah tersedia di sekolah seperti gambar dan torso.

\section{SIMPULAN}


Berdasarkan hasil penelitian mengenai ketersediaan dan pemanfaatan media pembelajaran berbasis TI di SMA Negeri SeKabupaten Deliserdang dapat disimpulkan bahwa:

a. Ketersediaan media pembelajaran berbasis TI di SMA Negeri SeKabupaten Deliserdang berada pada kategori sedang. Hal ini ditunjukkan dengan mean skor angket ketersediaan media pembelajaran berbasis TI jika dibandingkan kategori interval, berada pada kategori interval sedang.

b. Pemanfaatan media pembelajaran berbasis TI di SMA Negeri SeKabupaten Deliserdang berada pada kategori rendah. Hal ini ditunjukkan dengan mean skor angket pemanfaatan media pembelajaran berbasis TI jika dibandingkan dengan kategori interval, berada pada kategori rendah.

c. Jenis media yang paling tinggi penggunannya oleh guru biologi adalah berupa media pembelajaran dalam betuk Power Point.

d. Faktor yang mempengaruhi penggunaan media 1) Ketersediaan dan kondisi media, 2) ketersediaan jaringan internet, 3) guru kurang menguasai dan memahami dalam mengoperasikan media berbasis TI. Guru lebih mudah menggunakan media yang sudah tersedia di sekolah seperti gambar dan torso.

\section{DAFTAR RUJUKAN}

Anas, Muhammad, dkk. 2008. Pemanfaatan Teknologi Informasi dan Komunikasi (TIK) dalam Pembelajaran di Provinsi Sulawesi Tenggara. Jurnal Pendidikan dan Pembelajaran. Online. http://directory.umm.ac.id/tik/M uhammadAnas_PemanfaatanInf ormasidanKomunikasi(TIK). (Diakses 1 November 2018) Asabere, at al. 2012. Use of Information and Communication Technology (ICT) In Tertiary Education in Ghana: A Case Study of Electronic Learning (ELearning). Online. http://esjournals.org/journaloftec hnology/archive/vol2no1/vol2no 1_9. (Diakses 26 Oktober 2018)

Eliyadi, Marzuki, dan Arsan. 2013. Analisis Ketersediaan dan Pemanfaatan Media Pembelajaran Biologi SMA Kecamatan Tebas. Jurnal Pendidikan dan Pembelajaran. Online http://jurnal.untan.ac.id/index.ph p/jpdpb/article/view/3279

(Diakses 18 Oktober 2018)

Harliawan, dkk. 2014. Penggunaan Media Pembelajaran Berbasis TIK untuk Meningkatkan Hasil Belajar IPS Kelas VIII J SMP Negeri 5 Singaraja. Jurnal Pendidikan dan Pembelajaran. Online http://ejournal.undiksha.ac.id/ind ex.php/JJPE/article/viewFile/202 
4/1765 (Diakses 1 November 2018)

Kustandi, C. dan Bambang Sutjipto. 2013. Media Pembelajaran Manual dan Digital. Bogor: Ghalia Indonesia.

Kusuma, Wijaya, dkk. 2012. Teknologi Informasi dan Komunikasi Sekolah Menengah Pertama. Jakarta: Rajawali Cilik.

Munir. 2010. Kurikulum Berbasis Teknologi Informasi dan Komunikasi. Bandung: Alfabeta. Musfiqon, H. M. 2012. Panduan Lengkap Metodologi Penelitian Pendidikan. Jakarta: PT. Prestasi Pustakarya

Peraturan Pemerintah Republik Indonesia Nomor 19 Tahun 2005 tentang Standar Nasional Pendidikan. Online kemenag.go.id/file/dokumen/PP 1905.pdf (Diakses 16 Oktober 2018)

Priyatno, Duwi. 2012. Cara Kilat Belajar Analisis Data dengan SPSS 20.

Yogyakarta: CV. Andi Offset.

Sadiman, Arief S. dkk. 2007. Media Pendidikan. Jakarta: Raja Grafindo Persada.

Sejati, Nova D. R. I. 2011. Pemanfaatan Media Pembelajaran Pendidikan Kewarganegaraan Berbasis Teknologi Informasi dan
Komunikasi (TIK) pada SMP Negeri 5 Semarang. Online http://lib.unnes.ac.id/10761/

(Diakses 14 Oktober 2018)

Sutopo, Ariesto Hadi. 2012. Teknologi Informasi dan Komunikasi dalam Pendidikan. Yogyakarta: Graha Ilmu.

Tim Penyusun Pedoman Akademik Unnes. 2010. Panduan Penulisan Karya Ilmiah. Semarang: UNNES press. 